\title{
A novel modeling approach for the simulation of soil-water interaction in a highly plastic clay
}

\author{
Ramy Saadeldin $\cdot$ Amr Henni
}

Received: 23 October 2015/Accepted: 3 March 2016/Published online: 31 March 2016

(C) Springer International Publishing Switzerland 2016

\begin{abstract}
Formulation of unsaturated soil properties in a mathematical form is necessary for the computational modeling of water flow in soil deposits. To achieve this objective, it is essential to determine the soil-water characteristic curve (SWCC) in order to identify the soil response to transient water flow conditions. The volume-mass constitutive surfaces are other key properties that provide an overall theoretical framework for the soil state variables. In this paper, a bimodal SWCC equation was developed for a native clay deposit based on laboratory soil moisture-suction measurements. The proposed bimodal SWCC equation was formulated based on two distinct logistic power regression models. A factor quantifying the change in the soil hydraulic conductivity was also used to simulate the increase in the hydraulic conductivity of a cracked soil structure. The constitutive surfaces were then established based on the developed bimodal SWCC and representative consolidation test results. This study also attempted to perform an unsaturated seepage modeling analysis using the developed mathematical framework. The
\end{abstract}

R. Saadeldin $(\bowtie)$

Faculty of Engineering and Applied Science, University of Regina \& Amec Foster Wheeler Environment and Infrastructure, Regina, SK S4S 0A2, Canada

e-mail: ramysaadeldin@uregina.ca

\section{A. Henni}

Faculty of Engineering and Applied Science, University of Regina, Regina, SK S4S 0A2, Canada model was utilized to simulate the application of net surface flux on a soil column consisting of a highly plastic clay over a clay till. The sensitivity of the seepage analysis, attributable to variations in the SWCC and the hydraulic characteristics, was demonstrated. The results showed that the SWCC is a critical property controlling the modeling of the soil-water interaction, and it has a theoretical weight in performing a water seepage analysis. The use of a bimodal SWCC was capable of capturing the behavior of the top cracked clay layer leading to a rapid change in the volumetric water content with time.

Keywords Unsaturated soil - Bimodal SWCC · Desiccation cracks $\cdot$ Seepage analysis $\cdot$ Soil column

\section{Introduction}

Soils in arid and semi-arid regions of the world are typically characterized to be unsaturated and highly desiccated. These conditions may extend to a considerable depth, and the groundwater table may be located more than $30 \mathrm{~m}$ below the ground level (Fredlund and Rahardjo 1993a). Unsaturated soils experience wetting and drying cycles throughout the year, which in return, produce variations in the soil moisture content. The understanding of the unsaturated soil behavior is essential in making long-term predictions on the movement of water through soils 
(Fredlund and Rahardjo 1993a). The behaviour of unsaturated soils was found to be better identified using two independent stress components i.e., normal stress and matric suction (Bishop and Blight 1963). In addition, there are two main types of unsaturated soil property functions that are required for seepage modeling [i.e., unsaturated hydraulic conductivity function, and soil-water characteristic curve (SWCC)].

The infiltration of precipitation and/or surface water into low permeable soils (i.e., clays) is normally slow (Novak et al. 2000). Unsaturated clays are, however, characterized by a variety of heterogeneities (fractures/cracks) which affect water movement (Novak et al. 2000). The presence of cracks increases the water flow into the soil structure. The depth of cracking is, therefore, a crucial parameter that needs to be examined. In modeling the saturated soils, the hydraulic conductivity is typically characterized by a lumped parameter as it contains relatively stable macropores (Reynolds 1993). Unsaturated cracked soils, however, cannot be modeled using the same method. Soil cracks are unstable and their geometry changes with time depending upon the soil moisture content (Novak et al. 2000).

Another key property that is vital for the implementation of unsaturated soil principles is the soilwater characteristic curve (SWCC). The SWCC is used for the determination of unsaturated soil-atmosphere interaction (Wilson and Fredlund 2000) and unsaturated soil-structure interaction (Zhang 2004). The shape of the SWCC relies on the grain size distribution (Fredlund and Rahardjo 1993b; Vanapalli et al. 1998). The most typical shape of the SWCC is the unimodal SWCC, which represents two bending curves, only. However, recent studies presented a bimodal SWCC with two distinct levels of pore size distribution (de FN Gitirana Jr and Fredlund 2004; Satyanaga et al. 2013; Zhang and Chen 2005). Bimodal SWCCs have not been widely used or verified in the modeling of unsaturated soil deposits in different field applications. Consequently, in this study, a bimodal SWCC equation was developed, based on laboratory measurements of the soil suction at different volumetric water content (VWC) levels, and was then utilized to better simulate the highly plastic surficial clay layer.

The volume-mass constitutive surfaces provide an overall theoretical framework for soil parameters (i.e., water content, void ratio and degree of saturation) as a function of the two main independent stress state variables (i.e., normal stress and matric suction). The volume-mass constitutive surfaces are generally derived based on testing results. It is vital to construct this theoretical framework for modeling purposes for unsaturated soil deposits. In order to establish the most proper unsaturated volume-mass constitutive surfaces, this study utilized the developed bimodal SWCC equation. Then, the consolidation and swellshrink relationships were established using representative testing results.

A modeling approach was implemented to utilize the presented theoretical framework. The modeling program consisted of a soil column that was subjected to different net surface flux magnitudes. The transient water flow changed the stress state in the soil structure, and consequently, caused changes in the soil suction and VWC with time. In addition, the hydraulic conductivity functions were developed for the cracked and un-cracked soil layers. The modeling results were used to explain the change in soil suction and volumetric water contents (VWCs) at different depths below the ground surface and under different unsaturated soil conditions.

\section{Theoretical background}

Seepage models are mathematically formulated in the form of nonlinear partial differential equations and nonlinear soil properties (Fredlund and Rahardjo 1993b). These models involve the simulation of moisture flow through the soil structure. The development of the active soil zone is influenced by several factors, mainly the soil type, topography, the location of the ground water table, and air temperature. The location of the ground water table is controlled by the net surface flux [the difference between the downward flux (i.e., precipitation) and the upward flux (i.e., evapotranspiration)]. For arid or semi-arid regions, the groundwater level slowly decreases with time. However, it may remain relatively close to the ground surface under humid conditions ( $\mathrm{Ng}$ and Menzies 2007). The pore water pressure profile stays at a hydrostatic condition when there is zero net flux applied on the ground surface ( $\mathrm{Ng}$ and Menzies 2007).

The topic of desiccation cracks has been covered in the past in a number of research studies 
(Kodikara et al. 2002; Miller et al. 1998; Morris et al. 1992; Nahlawi and Kodikara 2006; Yesiller et al. 2000). The development of soil cracks influences the hydraulic conductivity of the nearsurface clay layer, and consequently, the moisture content changes with time. Albrecht and Benson (2001) found that cracking of the soil resulted in a noticeable increase in the hydraulic conductivity of a clay soil. Depending on the severity of the structural changes associated with the formation of desiccation cracks, the hydraulic conductivity may increase by several orders of magnitude (Johnston and Haug 1992). The depth of cracking is often required for defining the boundary conditions and conducting limit equilibrium analysis in geotechnical engineering (Lau 1987). Researchers developed various methods to compute the likely depth of desiccation cracking using various theoretical assumptions.

Fracture mechanics is a technical approach defining the crack propagation criteria in materials mainly by evaluating the stress and strain fields near the crack tip (Hanson et al. 1994). The basic concept of crack propagation is that it will occur if the energy available for crack growth is sufficient to overcome the material resistance (Griffith 1921). This resistance typically includes the surface energy, plastic work, or other types of energy dissipation associated with the development of a crack. From a mechanical point of view, the stress distribution at the crack tip can be assumed, as presented in Fig. 1 and, therefore, can be computed as a function of the material fracture toughness and the applied tensile stress. Several studies (Blight and Williams 1971; Briones and Uehara 1977; Raats 1984) applied the Griffith's brittle fracture theory on the desiccation cracking of soils. The fracture toughness was defined as a mechanical parameter indicating the ability to resist fracture failure. The relationship between the fracture toughness and other mechanical parameters such as tensile strength were also previously examined (Wang et al. 2007). However, Corte and Higashi (1964) reported that cracking by desiccation is somehow different from mechanical cracking mainly because of the loss in the material mass during the process.

Hydraulic conductivity is a key soil property controlling the soil-water interaction. In principle, water flows through the pore spaces that are filled with

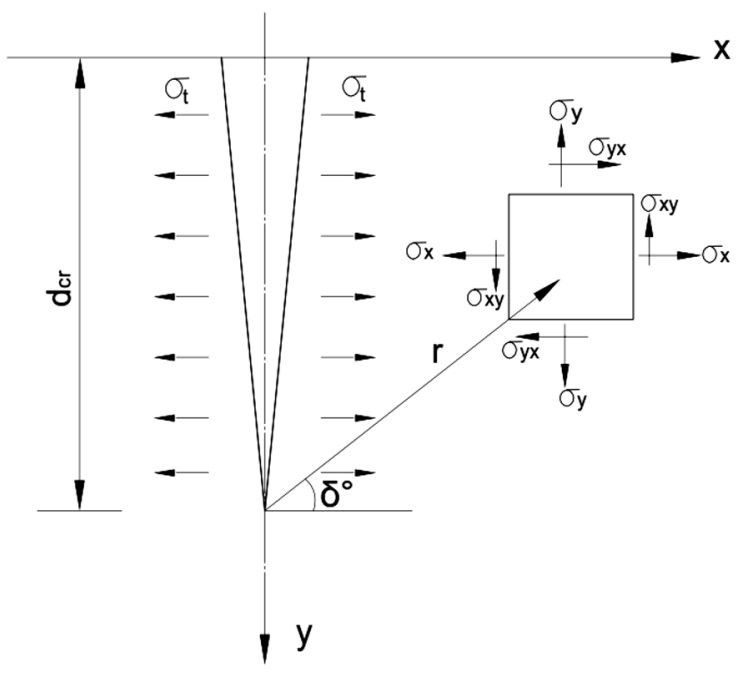

Fig. 1 A theoretical model for the mechanical mechanism of soil cracking [after Anderson (2005)]

water. Therefore, the soil hydraulic conductivity is a function of the water content or soil suction for unsaturated soils (Childs and Collis-George 1950). The lower the moisture content is, the lower the hydraulic conductivity value is for unsaturated soils because of the lower availability of saturated pores. Therefore, the hydraulic conductivity of unsaturated soil should be considered as a function of water content or matric suction (Gallage et al. 2013). As a general trend, the hydraulic conductivity of soil decreases dramatically with the reduction in the degree of saturation ( $\mathrm{Ng}$ and Menzies 2007). Due to the difficulty of measuring the hydraulic conductivity function, methodologies to estimate the physical properties of the pore space provided an insight in predicting the saturated-unsaturated hydraulic conductivity. Therefore, prediction methods are frequently used and are mostly based on the soil-water retention characteristics (Durner 1994).

The soil-water characteristic curve (SWCC) is another critical soil property influencing the unsaturated soil behavior. Generally, the capacity of finegrained soils to retain water depends on the soil fabric including macropores, mesopores, and micropores (Elkady 2014; Mitchell 1993). The native soil structure and grain size distribution are contributing factors affecting the shape of the SWCC. The bimodal curve defines two air entry values and two residual volumetric water contents including near horizontal or horizontal intermediate segment 
(Elkady 2014). Bimodal SWCCs are typically observed in soils with cracks, and can be utilized to simulate changes in soil moisture content in the field. Hence, a bimodal SWCC can, more realistically, describe the current problem.

There is a number of volume-mass constitutive models that were established for unsaturated soils (Pham 2005). These constitutive models were developed as an extension of the saturated soil constitutive equations and incorporated the use of two independent soil properties (total normal stress and soil suction). Fredlund and Rahardjo (1993b) presented the theoretical basis for developing the volume-mass constitutive surfaces for saturated-unsaturated soils. Both void ratio and water content for unsaturated soils can be defined as functions of the net normal stress and soil suction. The constitutive equations can, therefore, be plotted as surfaces on a threedimensional plot, with each abscissa representing one of the stress state variables, and the ordinate representing a soil volume-mass property (Zhang 2004; Fredlund and Rahardjo 1993b). The constitutive relationships provide a framework for understanding how soil behaves under different loading conditions, and they can be formatted in finite element and finite difference codes for use in numerical analysis.

\section{Subsurface soil conditions}

The surficial geology of the city of Regina area experienced in the past some glacial ice advances, retreats, and meltdowns. Stratified drift deposits, more than $200 \mathrm{~m}$ in depth, cover the Bearpaw shale below the area (Mollard et al. 1998). The soil profile consists mainly of lacustrine soil sediments deposited from about 14,000 years (Christiansen 1979) specifically during the last glaciation phase advance (Christiansen and Sauer 2002). The uppermost surficial deposit near the existing grade consists of highly plastic lacustrine clay with a considerable thickness of 5-12 m, depending on the location. The high swell-shrink potential of the clay in the area is resulting from the high clay content $(>60 \%)$, and the dominance of smectite or montmorillonite minerals in the clay (Anderson 2010).

The geotechnical soil properties were obtained from field instrumentation and laboratory research programs for a site located in Regina, Saskatchewan. Soils encountered at the field site were identified by two test holes, TH1 and TH2, which were approximately $8 \mathrm{~m}$ apart as discussed in $\mathrm{Hu}$ and $\mathrm{Vu}$ (2011). The soil profile obtained from these two test holes were plotted in Fig. 2. Tables 1 and 2 show the key geotechnical index properties for the native soil deposits, Regina clay and clay till. The measured water content of Regina clay ranged from 23 to $35 \%$. The specific gravity and average void ratio of the clay were found to be 2.73 and 0.95 , respectively. The liquid limit, plastic limit, and plasticity index were measured to be approximately 79,30 , and $49 \%$ respectively. In general, the clay is considered nonplastic when it has a moisture content that is less than the plastic limit (White 1949). Therefore, the clay would likely be cracked or it has a tendency to develop cracks with any reduction in its moisture content. Based on the soil moisture content results shown in Fig. 2, the upper 2-3 $\mathrm{m}$ of the clay were found to have a natural moisture content that was less than that of the lower clay layer. In addition, the upper clay layer was also found to have an average moisture content that was less than the plastic limit demonstrating that the clay was desiccated. $\mathrm{Hu}$ and $\mathrm{Vu}$ (2011) also illustrated that large surficial cracks, approximately $10 \mathrm{~mm}$ wide, were observed in the study area.

The grain size distribution curves (GSDCs) for Regina clay and the clay till are plotted in Fig. 3. The SWCC for the clay till was estimated based on the index properties and the GSDC using the methods documented by (Fredlund and Xing 1994; Fredlund et al. 2002) as shown in Fig. 4. The development of the SWCC for the naturally deposited clay soil (Regina clay) was estimated using fits from both the Fredlund and Xing fit and the bimodal equations as discussed in detail later in the manuscript. The saturated hydraulic conductivity of Regina clay was measured to range from $1.6 \times 10^{-9}$ to $2.8 \times 10^{-8} \mathrm{~m} / \mathrm{s}$ (Hu and $\mathrm{Vu}$ 2011). The saturated hydraulic conductivity of the clay till was estimated, using Hazen's equation (Hazen 1892), and based on the grain size distribution, to be $1.0 \times 10^{-8} \mathrm{~m} / \mathrm{s}$. The unsaturated hydraulic conductivity functions for Regina clay and the clay till were estimated based on the Leong and Rahardjo equation and using the saturated hydraulic conductivity as shown in Fig. 5 (Leong and Rahardjo 1997). 


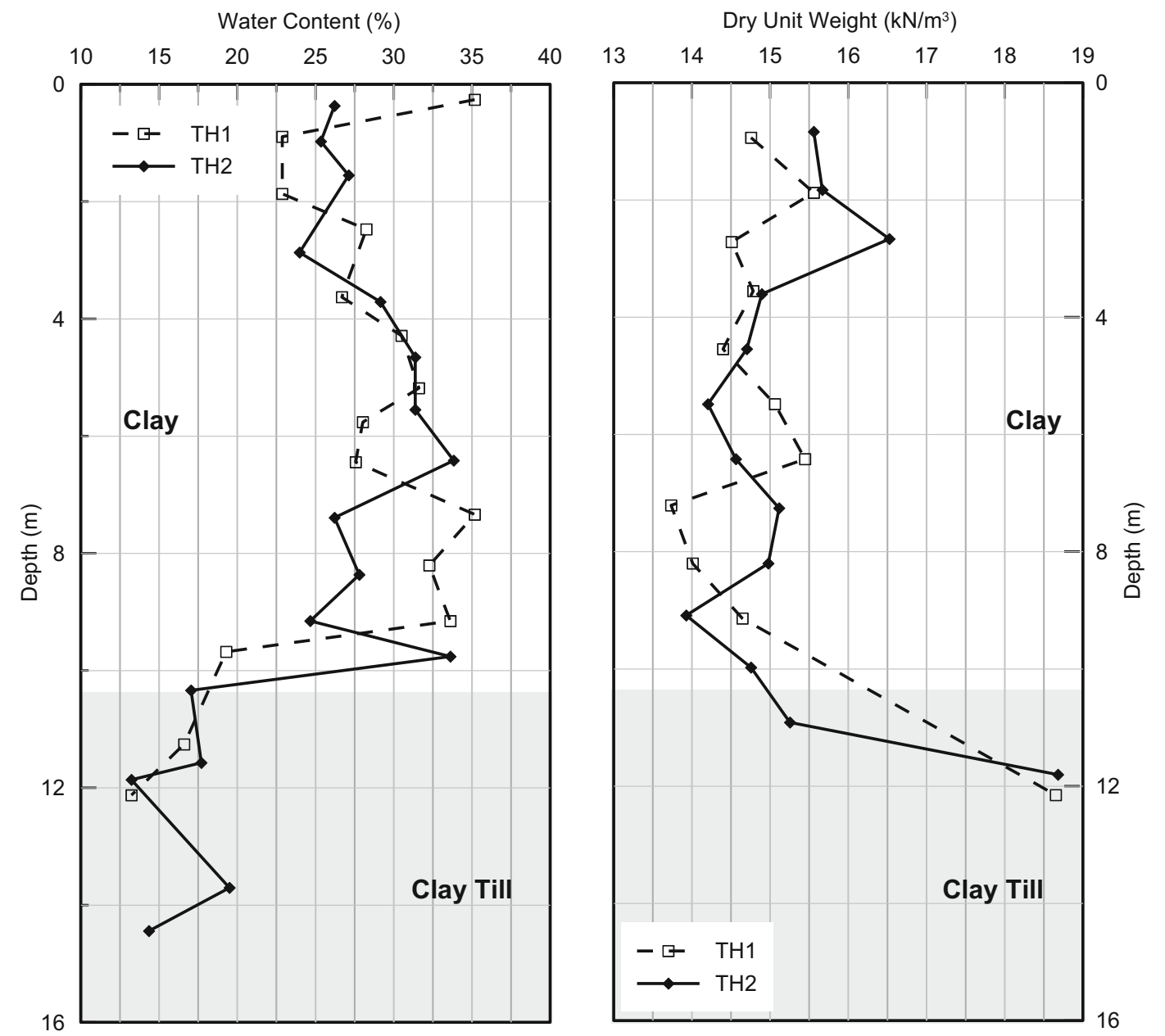

Fig. 2 Water content (gravimetric) and dry unit weight profiles at two test holes (TH1 and TH2) at the field site

Table 1 The geotechnical properties of Regina clay

\begin{tabular}{ll}
\hline Soil property (unit) & Value \\
\hline Natural water content, w (\%) & $23-35$ \\
Specific gravity & 2.73 \\
Void ratio, e & 0.95 \\
Liquid limit, LL (\%) & 79 \\
Plastic limit, PL (\%) & 30 \\
Plastic index, PI $(\%)$ & 49 \\
Saturated hydraulic conductivity $(\mathrm{m} / \mathrm{s})$ & $1.6 \times 10^{-9}-2.8 \times 10^{-8}$ \\
Gravel content $(\leq 62 \mathrm{~mm})(\%)$ & $0.0-0.4$ \\
Sand content $(\leq 5 \mathrm{~mm})(\%)$ & $0.1-1.3$ \\
Silt and clay content $(\leq 74 \mathrm{~mm})(\%)$ & $98.7-99.9$ \\
\hline
\end{tabular}


Table 2 The geotechnical properties of the clay till

\begin{tabular}{ll}
\hline Soil property (unit) & Value \\
\hline Natural water content, w (\%) & $12-20$ \\
Liquid limit, LL (\%) & 41 \\
Plastic limit, PL (\%) & 17 \\
Plastic index, PI (\%) & 24 \\
Estimated saturated hydraulic conductivity $(\mathrm{m} / \mathrm{s})$ & $1.0 \times 10^{-8}$ \\
Gravel content $(\leq 62 \mathrm{~mm})(\%)$ & $0-3.6$ \\
Sand content $(\leq 5 \mathrm{~mm})(\%)$ & $4.2-31.8$ \\
Silt and clay content $(\leq 74 \mathrm{~mm})(\%)$ & $66.5-95.8$ \\
\hline
\end{tabular}

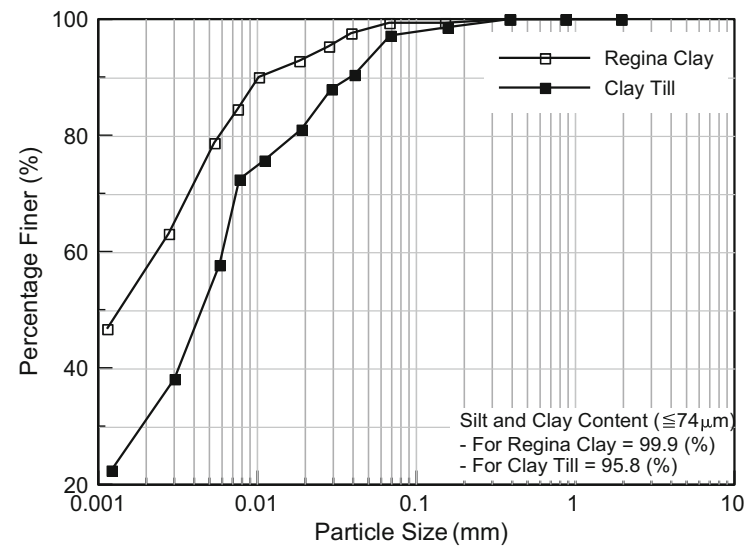

Fig. 3 Grain size distributions

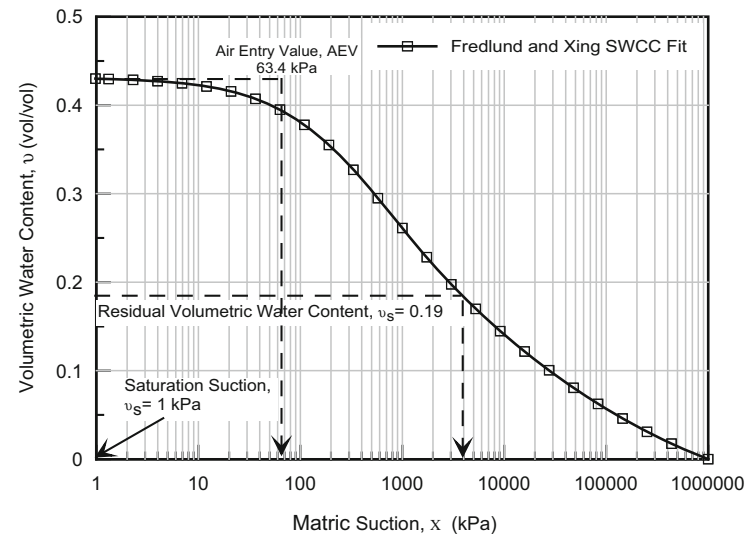

Fig. 4 Soil-water characteristic curve (SWCC) for the clay till

\section{Cracking depth formulation}

Morris et al. (1992) proposed an analytical approach based on the linear elastic theory to predict the cracking depth for various soil parameters and suction

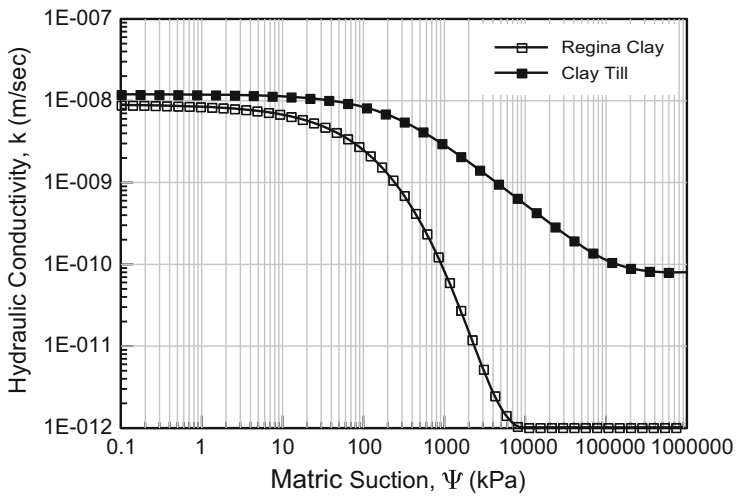

Fig. 5 Hydraulic conductivity functions for Regina clay and clay till

values. Equation 1 shows the relationship between cracking depth, depth to ground water table, and surface suction (Morris et al. 1992). The approach assumed that the soil suction decreases linearly from the suction at the ground surface $\left(\mathrm{S}_{0}\right)$ to the value zero at the ground water table (depth $\mathrm{d}_{\mathrm{w}}$ ) as presented in Eq. 2. The relationship also incorporated a coefficient representing the shear strength of the soil (Eqs. 3-5).

$\mathrm{d}_{\mathrm{cr}}=\frac{\mathrm{S}_{o}}{\frac{\mathrm{S}_{\mathrm{o}}}{\mathrm{d}_{\mathrm{w}}}+\mathrm{E}_{\mathrm{c}}}$

$\mathrm{S}=\mathrm{S}_{0}\left(1-\frac{\mathrm{Z}}{\mathrm{d}_{\mathrm{w}}}\right)$

$\mathrm{E}_{\mathrm{c}}=\frac{\mu \gamma}{1-2 \mu-(1-\mu) \alpha_{T} \tan \phi^{b} \cot \phi^{\prime}}$

$\alpha_{\mathrm{T}}=0.5 \tan \phi^{\prime}$

$\phi^{\mathrm{b}}=\phi^{\prime}-5^{\circ}$

where, $d_{c r}$ is the cracking depth, $S$ is the suction, $S_{0}$ is the suction at the ground surface, $\mathrm{z}$ is the depth below the ground surface, $d_{w}$ is the distance from the ground surface to the ground water table, $\mathrm{E}_{\mathrm{c}}$ is the compression modulus, $\mu$ is the Poisson's ratio, $\gamma$ is the unit weight of soil, $\alpha_{\mathrm{T}}$ is the coefficient for the angle of shearing resistance, $\phi^{\prime}$ is the soil friction angle with respect to the total stress, and $\phi^{\mathrm{b}}$ is soil friction angle with respect to the soil suction.

Lau (1987) and Fredlund and Rahardjo (1993b) published a mathematical method for determining the depth of cracking as a function of shear strength based on the Rankine theory of lateral earth pressure as 
presented in Eq. 6. The method assumed that the coefficient of earth pressure at rest and the net horizontal stress are equal to zero at the bottom of the soil crack. Figure 6 shows a typical mathematical model for desiccation cracks and a representative soil suction profile presenting the negative pore-water pressure as a linear function of distance above the groundwater table. The equation is a function of the groundwater depth, elasticity ratio, and other soil properties such as the unit weight and Poisson's ratio.

$\mathrm{d}_{\mathrm{cr}}=\frac{\mathrm{d}_{\mathrm{w}}}{1+\frac{\mu \gamma}{(\mathrm{E} / \mathrm{H}) \gamma_{\mathrm{w}} \mathrm{f}_{\mathrm{w}}}}$

where, $d_{c r}$ is the depth of cracking, E/H is the elasticity parameters ratio. For an initially saturated clay, it ranges from 0.15 to 0.2 (Lau 1987), $\gamma_{\mathrm{w}}$ is the unit weight of water, and $f_{w}$ is a variable used to permit the pore-water pressure to be represented as a percentage of the hydrostatic profile. Other variables were previously defined.

Values of the estimated depth of cracking were determined using the two approaches discussed above. At the time of the field investigation, there was no definite ground water table up to the explored depth of $16 \mathrm{~m}$. Due to the relatively granular and seepage nature of the clay till, the ground water depth was then assumed to be either located at the maximum explored depth $(16 \mathrm{~m})$ or just beneath the clay deposit $(9.5 \mathrm{~m})$. The assumed ground water table levels were considered reasonably representative of both highly wet conditions during rainy conditions and the creation of a perched groundwater table within the clay till. Figures 7, 8 and 9 show the variation in estimated cracking depth at different ground water depths and different soil conditions.

It was found that the linear elastic method resulted in higher estimated cracking depths. Based on the analytical results, a cracking depth of up to $3 \mathrm{~m}$ can be expected and reasonably represents the field conditions as previously discussed in this manuscript. Based on the results shown in Fig. 7, a cracking depth of $3 \mathrm{~m}$ may be expected at a surface suction of $100 \mathrm{kPa}$. In addition, based on the results shown in Figs. 8 and 9, a cracking depth of $3 \mathrm{~m}$ may, however, be expected at an elasticity ratio $(\mathrm{E} / \mathrm{H})$ of approximately 0.15 and 0.11 for a ground water depth of 16 and $9.5 \mathrm{~m}$, respectively, assuming that the hydrostatic profile factor is approximately 1.5 .

\section{Hydraulic conductivity formulation}

The top $3 \mathrm{~m}$ of the clay layer were assigned a higher hydraulic conductivity to simulate the effect of the
Fig. 6 A typical desiccated soil profile and idealized matric suction profile [after Lau (1987)]

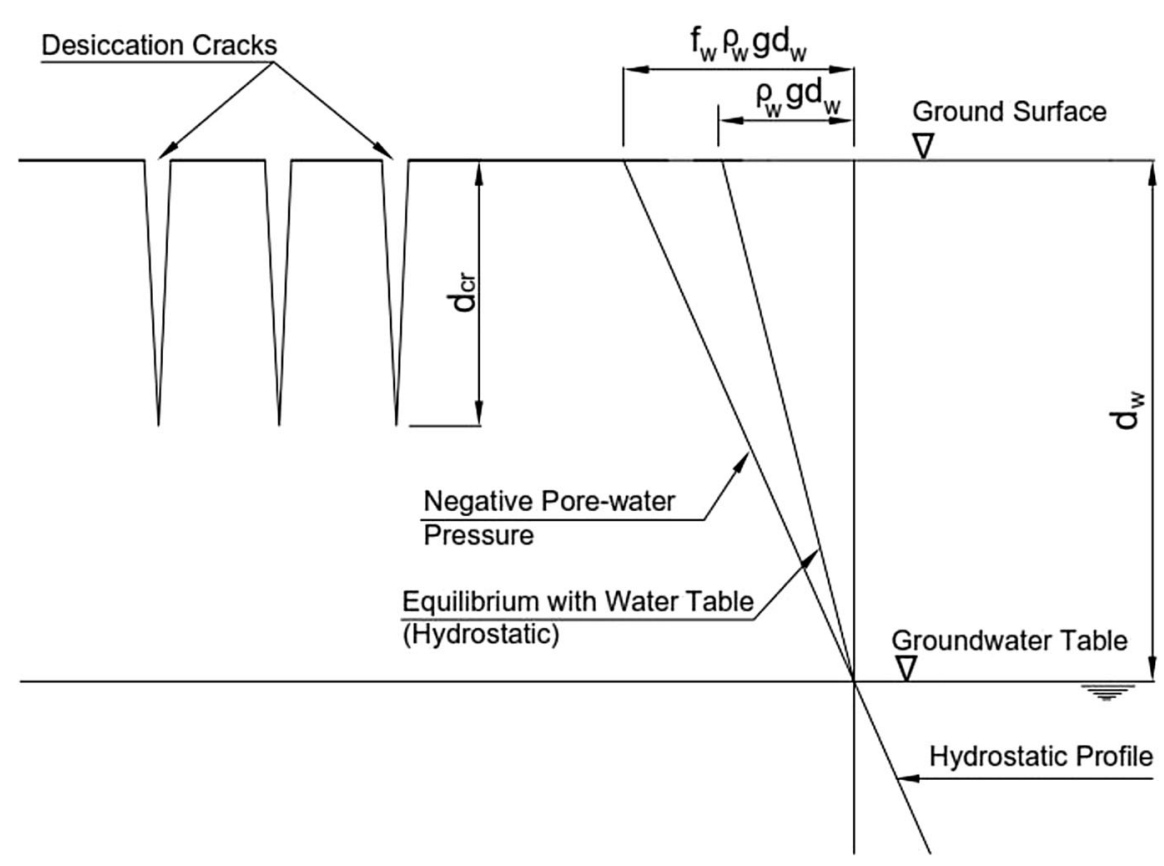




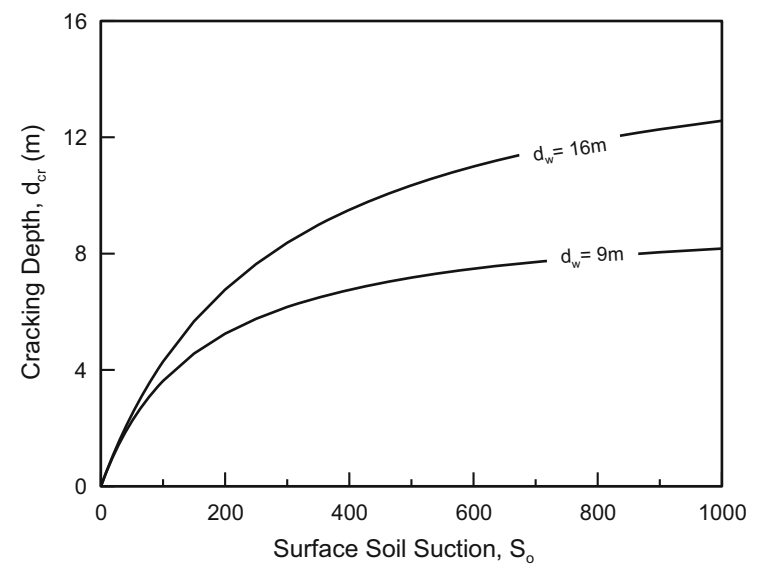

Fig. 7 Estimated cracking depth at different ground water depths (linear elastic approach)

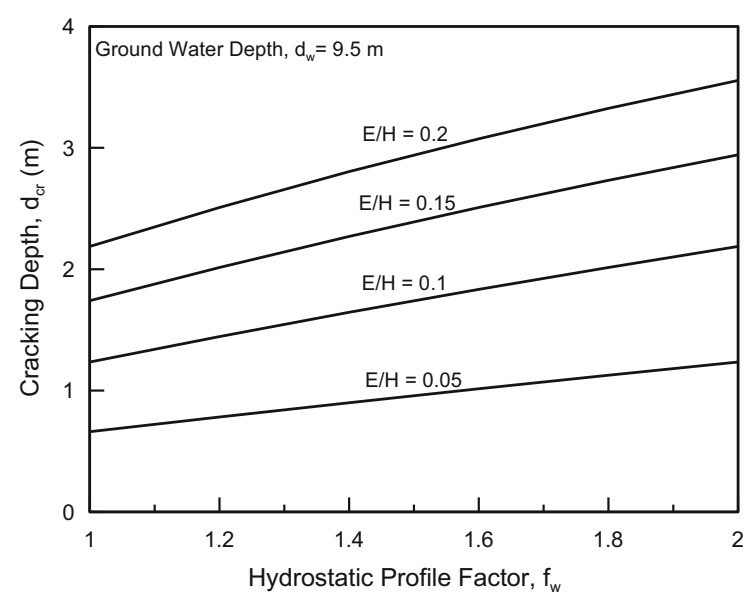

Fig. 8 Estimated cracking depth at a ground water depth of $9.5 \mathrm{~m}$ (shear strength approach)

seasonal development of desiccation cracks. A hydraulic conductivity factor labeled $\left(f_{c r}\right)$ was assumed to stand for the increase in the hydraulic conductivity due to the propagation of cracks. The hydraulic conductivity factor was defined as the ratio between the hydraulic conductivity of the cracked soil structure to the hydraulic conductivity of the natural soil (un-cracked) structure $\left(\mathrm{f}_{\mathrm{cr}}=\mathrm{k}_{\mathrm{cr}} / \mathrm{k}_{\mathrm{n}}\right)$. In view of the fact that the development of soil cracks is a dynamic process and is generally associated with the water infiltration/exfiltration processes, the factor was then defined to be a function of the soil suction as a stress state reflecting the soil moisture conditions.

The maximum increase in the hydraulic conductivity (a value represented as $f_{\max }$ ) is specified at the

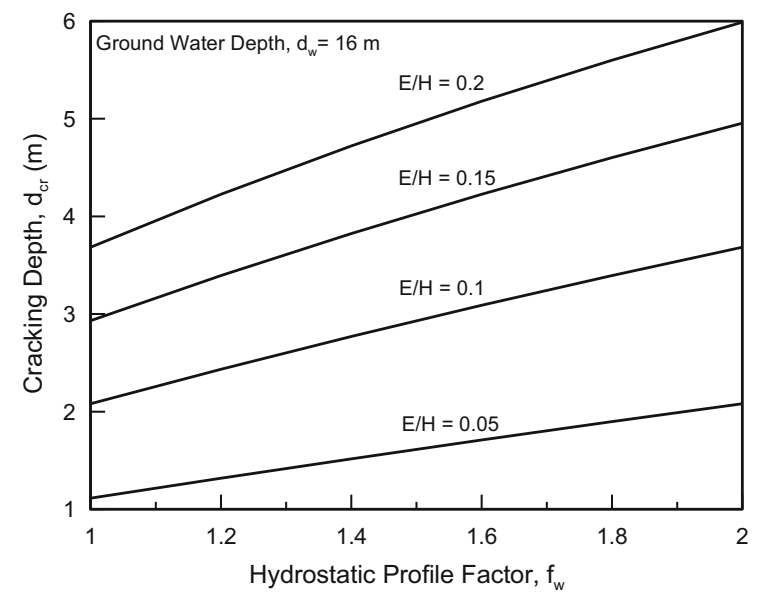

Fig. 9 Estimated cracking depth at a ground water depth of $16 \mathrm{~m}$ (shear strength approach)

residual VWC and residual soil suction $\left(\Psi_{\mathrm{r}}\right)$ assuming that the cracks are fully developed. However, the factor was assigned a value of 1 at completely saturated condition $\left(\Psi_{\text {sat }}\right)$. Using this definition, Eq. 7 was incorporated into the modeling program to predict the final hydraulic conductivity of the top soil layer with time.

$\mathrm{f}_{\mathrm{cr}}=1+\left[\frac{\Psi-\Psi_{\text {sat }}}{\Psi_{\mathrm{r}}-\Psi_{\text {sat }}}\right]\left(\mathrm{f}_{\max }-1\right)$

where, $\mathrm{f}_{\mathrm{cr}}$ is the hydraulic conductivity factor defining the ratio between cracked and un-cracked soil condition, $\mathrm{f}_{\max }$ is a variable used to represent the maximum hydraulic conductivity ratio between cracked and uncracked soil at an entirely dry condition, $\Psi$ is the soil suction, $\Psi_{\mathrm{r}}$ is the soil suction corresponding to the residual VWC, and $\Psi_{\text {sat }}$ is the soil suction corresponding to the saturated VWC.

\section{Development of bimodal SWCC}

A bimodal SWCC was developed using the measured data sets obtained from laboratory testing of the soil suction at different water content levels. Figure 10 shows the measured data points for the field samples as two sets, namely (1) and (2) that were obtained using pressure plate and filter paper testing methods as discussed in $\mathrm{Hu}$ and $\mathrm{Vu}$ (2011). The proposed equation of the bimodal SWCC was developed using two distinct logistic regression models fitting the laboratory 


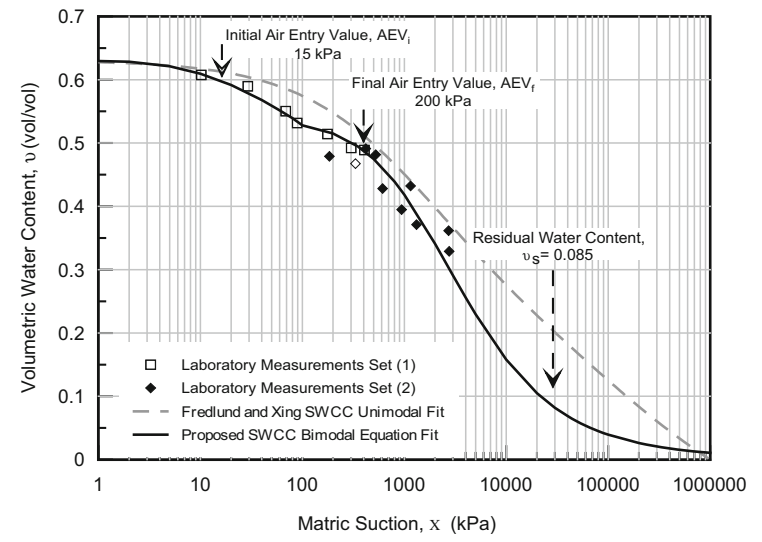

Fig. 10 Bimodal SWCC and laboratory soil suction measurements

data sets before and after a turning point. The turning point appeared at a soil suction of $100 \mathrm{kPa}$ as shown in Fig. 10. The developed equation and the corresponding fitting parameters are represented by Eq. 8. It is important to mention that the presented fitting equation was found to match a previous SWCC unimodal equation proposed by Gardner (1958). However, the fitting parameters are predicted in the form of two sets, in order to establish a bimodal curve. Figure 10 also shows the predicted SWCC using the Fredlund and Xing fitting equation and based on the GSDC of the native clay.

$\theta=\left[\frac{\theta_{\text {sat }}}{1+\left(\frac{\log \Psi}{a_{i}}\right)^{b_{\mathrm{i}}}}\right]_{\theta_{\text {sat }}, 1}^{\theta_{\mathrm{t}}, \Psi_{\mathrm{t}}}+\left[\frac{\theta_{\mathrm{t}}}{1+\left(\frac{\log \Psi}{\mathrm{a}_{\mathrm{f}}}\right)^{\mathrm{b}_{\mathrm{f}}}}\right]_{\theta_{t}, \Psi_{\mathrm{t}}}^{0,10^{6}}$

where, $\theta$ is the volumetric water content (VWC) (vol/ vol), $\theta_{\mathrm{t}}$ and $\Psi_{\mathrm{t}}$ are the volumetric water content and soil suction at the turning point $(0.53$ and $100 \mathrm{kPa}$, respectively), $\Psi$ is the soil suction $\left(1 \leq \Psi \leq 10^{6}\right.$ $\mathrm{kPa}), \theta_{\text {sat }}$ is the saturated volumetric water content (0.63) (vol/vol), $a_{i}$ and $b_{i}$ are the curve fitting parameters for the first part of the curve (3.844, and 2.542 , respectively), and $a_{\mathrm{f}}$ and $b_{\mathrm{f}}$ are the curve fitting parameters for the second part of the curve (3.56, and 7.464 , respectively).

The developed bimodal SWCC fitted well the laboratory data measurements and showed two air entry values as initial and final values of 15 and $200 \mathrm{kPa}$, respectively. The bimodal SWCC was, however, positioned below the unimodal fit. Also,

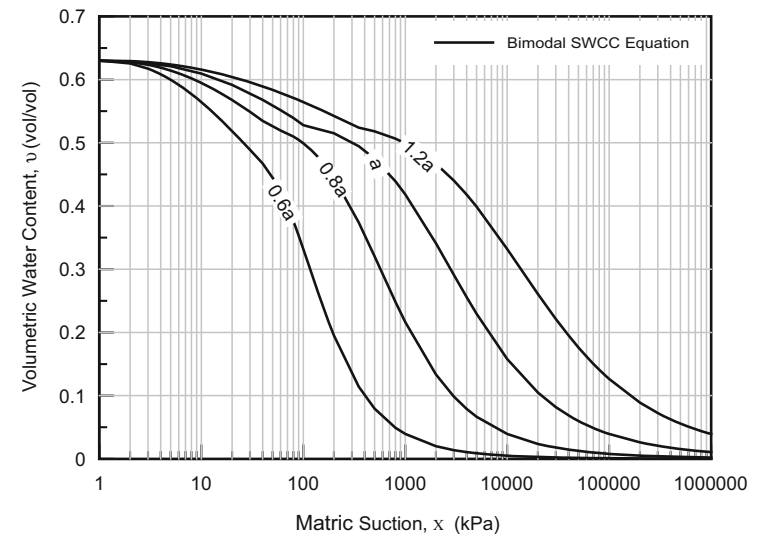

Fig. 11 SWCC shapes at different values for the fitting parameter (a)

with an increase in the soil suction, the difference between the unimodal and bimodal SWCCs increased. This difference was considered as a good representation of the divergence between the bases of developing each of these curves. Unimodal SWCCs established based on the grain size distribution of the soil may not necessarily be representative of the native soil structure . However, it is important to note that clay of dispersed structure would result in a different soil-water interaction behavior than that of fluctuated structure even if both have the same grain size. The bimodal was, alternatively, developed based on a reasonable range of measured VWC and soil suction values. Therefore, it was able to capture the structure of the clay. By comparing both the unimodal and bimodal soil curves, it is clear that the bimodal curve at the same soil suction shows greater water moisture reduction than the unimodal one.

A parametric study was conducted to determine the SWCC using different values of the fitting parameters. Figures 11 and 12 show the effect of the change in fitting parameters on the SWCC shape. The fitting parameters can be used to plot a wide range of the variation in soil suction and VWC. The variation in the parameter (a) did not result in a change in the slopes of the SWCC, and it controlled more the position of the SWCC in relation to the best fit. However, the parameter (b) had more influence on the slope of the plotted SWCC. As shown in the figure, the bimodal SWCC consisted of two SWCC functions that were 


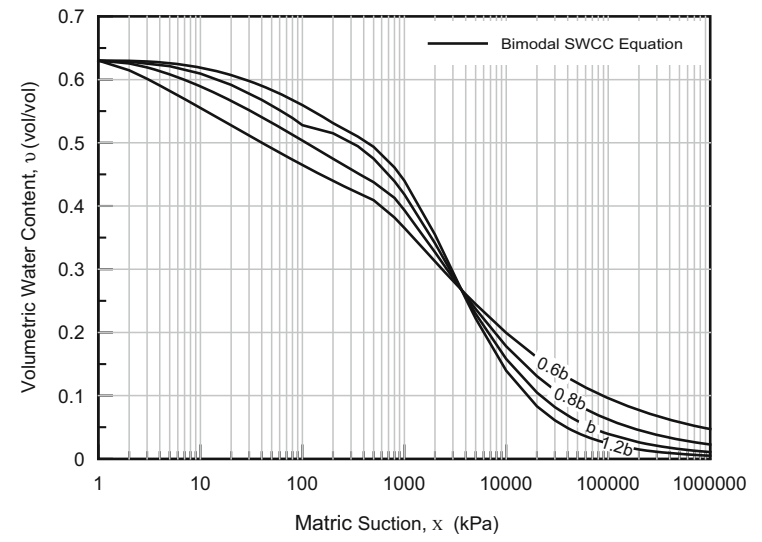

Fig. 12 SWCC shapes at different values for the fitting parameter (b)

superimposed to establish one function for the cracked soil as defined by Durner (1994). The two SWCC functions along with their distinct parameters were developed representing the intact and cracked parts of the soil. The bimodal SWCC was found to be a practical tool to simulate the soil as a dual-porosity medium (Köhne et al. 2002). Using the developed bimodal SWCC, the soil behavior can then be modeled as a combination of two materials averaged over the whole soil volume demonstrating the change in the soil behavior caused by the soil cracks (Fredlund et al. 2010).

\section{Volume-mass constitutive relationships}

The unsaturated soil structure interaction under loading and unloading as well as wetting and drying processes can be well understood using the volumemass constitutive surfaces. These constitutive surfaces define the primary soil volume-mass variables (i.e., void ratio, water content and degree of saturation) as a function of the two independent stress state variables (i.e., matric suction and net normal stress) forming 3D surfaces. Using these constitutive surfaces, all soil parameters can be determined over the entire ranges of possible pore pressure and stress values. Matyas and Radhakrishna (1968) recommended that the soil element state can be graphically characterized as a point in a system (i.e., a state point) where the coordinate axes represent the state parameters so that changes in the stress state are defined as a state path. Fredlund and Rahardjo (1993b) presented the main principles to construct $3 \mathrm{D}$ volume-mass constitutive surfaces as summarized below (Zhang 2004):

1. Void ratio versus net normal stress plot when the matric suction is equal to zero, $\left[\mathrm{e}=f\left(\sigma-\mathrm{u}_{\mathrm{a}}\right.\right.$, $\left.\left.\mathrm{u}_{\mathrm{a}}-\mathrm{u}_{\mathrm{w}}=0\right)\right]$,

2. Void ratio versus suction plot when the net normal stress is equal to zero $\left[\mathrm{e}=f\left(\sigma-\mathrm{u}_{\mathrm{a}}=0\right.\right.$, $\left.u_{\mathrm{a}}-\mathrm{u}_{\mathrm{w}}\right)$ ],

3. Water content versus net normal stress plot when the matric suction is equal to zero, $\left[\mathrm{w}=f\left(\sigma-\mathrm{u}_{\mathrm{a}}\right.\right.$, $\left.\left.\mathrm{u}_{\mathrm{a}}-\mathrm{u}_{\mathrm{w}}=0\right)\right]$,

4. Water content versus suction plot when net normal stress is equal to zero, $\left[\mathrm{w}=f\left(\sigma-\mathrm{u}_{\mathrm{a}}=0, \mathrm{u}_{\mathrm{a}}-\mathrm{u}_{\mathrm{w}}\right)\right]$,

5. Degree of saturation versus mechanical stress plot when the matric suction is equal to zero $\left[\mathrm{S}=f\left(\sigma-\mathrm{u}_{\mathrm{a}}, \mathrm{u}_{\mathrm{a}}-\mathrm{u}_{\mathrm{w}}=0\right)\right]$, and

6. Degree of saturation versus matric suction plot when the net normal stress is equal to zero $\left[\mathrm{S}=f\left(\sigma-\mathrm{u}_{\mathrm{a}}=0, \mathrm{u}_{\mathrm{a}}-\mathrm{u}_{\mathrm{w}}\right)\right]$.

To establish the constitutive relationships, the predicted bimodal SWCC was used to define the relationship between the matric suction and VWC. Figure 13 represents the relationship between the normalized VWC and mean normal stress as defined in Eq. 9. Figure 14 shows the different plots for the relationship between the VWC and net normal stress using different values for the input fitting parameters. In addition, previous laboratory measurements presented by Fredlund (1967) were used to define the relationship between the normalized VWC and mean normal stress as defined in Eq. 10. Figure 15 presents

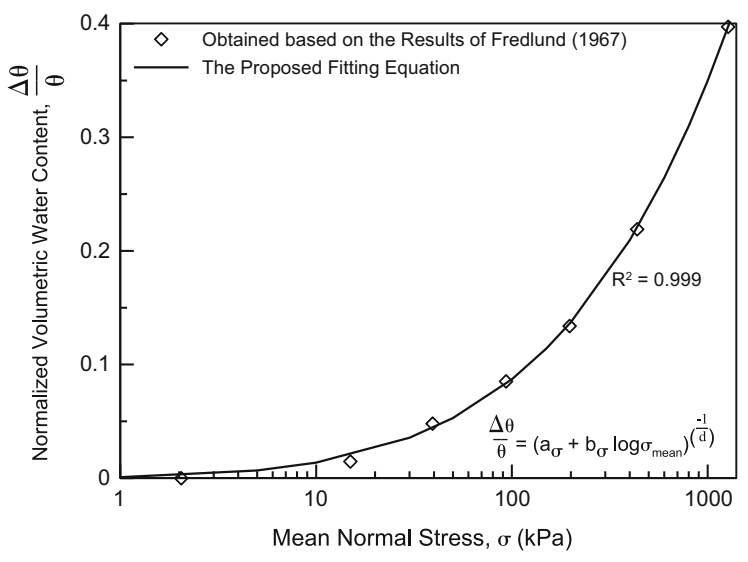

Fig. 13 Normalized volumetric water content versus mean normal stress 


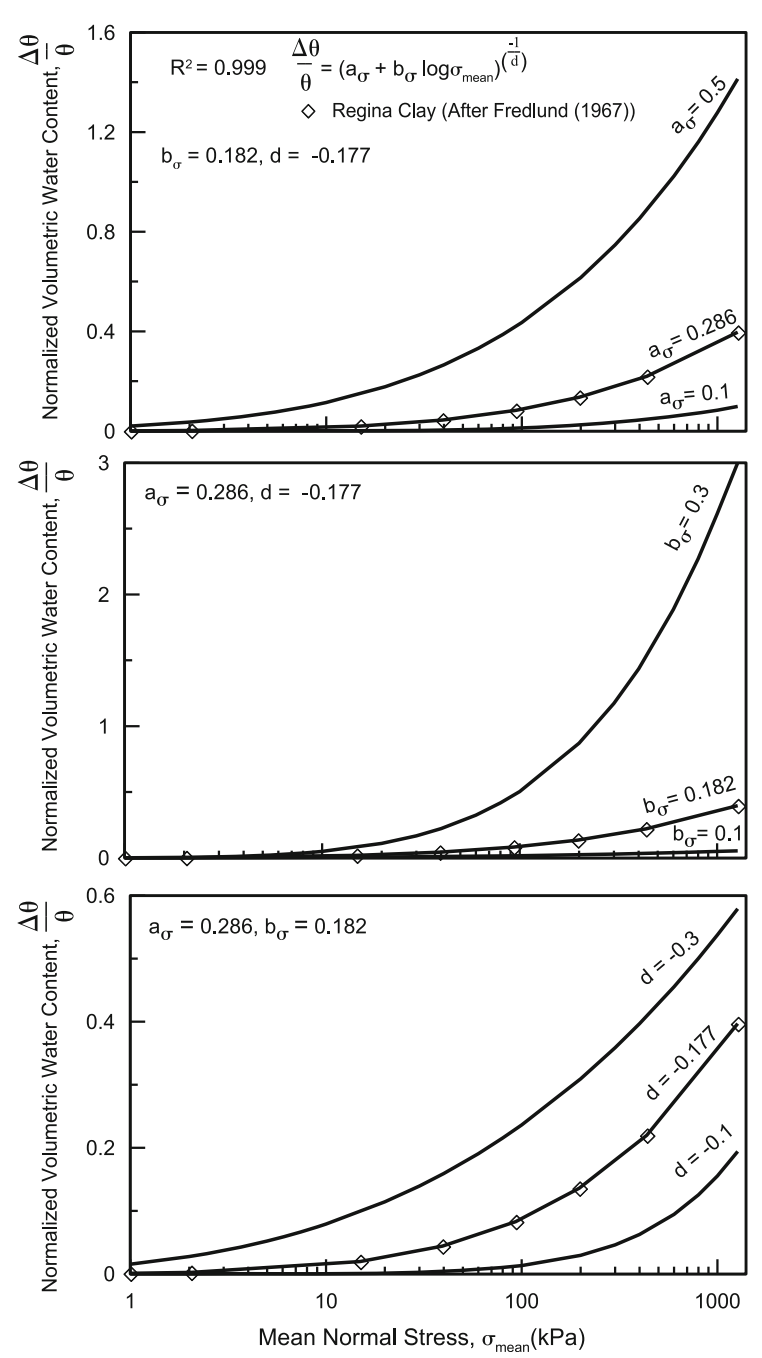

Fig. 14 Parametric analysis for the normalized volumetric water content versus mean normal stress relationship

the adopted relationship between the VWC and degree of saturation. Figure 16 presents the various shapes of the relationship using different fitting parameters. Figures 17, 18 and 19 show the predicted volumemass constitutive surfaces. These constitutive surfaces were used to predict the unsaturated soil properties of native clay. The plotted constitutive surfaces demonstrate the change in the unsaturated soil properties for a range of the net normal stress and soil suction.

$\frac{\Delta \theta}{\theta}=\left(\mathrm{a}_{\sigma}+\mathrm{b}_{\sigma} \log \sigma_{\text {mean }}\right)^{\left(-\frac{1}{\mathrm{~d}_{\sigma}}\right)}$

where, $\mathrm{a}_{\sigma}, \mathrm{b}_{\sigma}$, and $\mathrm{d}_{\sigma}$ are fitting parameters, and $\sigma_{\text {mean }}$ is the net normal stress.

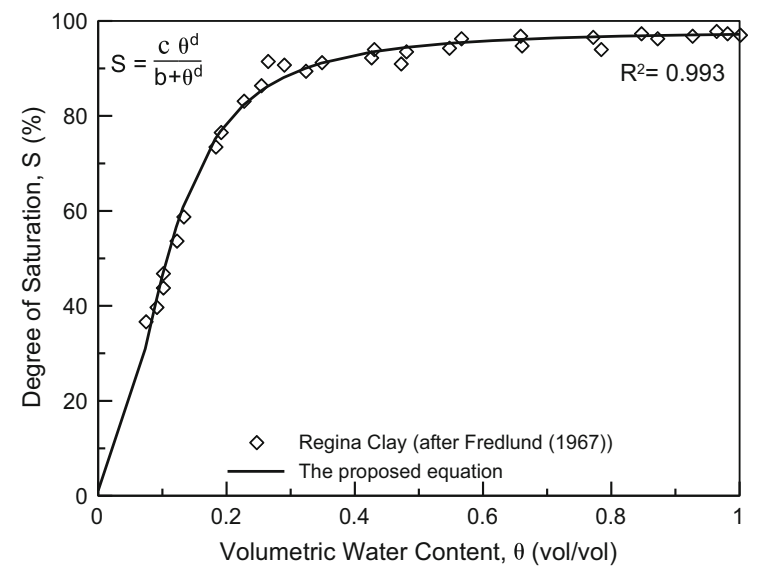

Fig. 15 Degree of saturation versus volumetric water content

For Regina clay, the best-fit curves were found to have the following values:

$\mathrm{a}_{\sigma}=0.285593, \mathrm{~b}_{\sigma}=0.1815003$, and

$\mathrm{d}_{\sigma}=-0.17729$

$S=\frac{c \theta^{d}}{b+\theta^{d}}$

where, $b, c$, and $d$ are fitting parameters, $S$ is the degree of saturation, and $\theta$ is the volumetric water content (VWC) ( vol/vol).

For Regina clay, the best-fit curves were found to have the following values:

$\mathrm{b}=0.007576, \mathrm{c}=97.92621$, and $\mathrm{d}=2.17763$

Since the volume-mass constitutive surfaces have been established, if two stress state variables including (net normal stress or matric suction) are identified, other parameters such as void ratio (e), VWC $(\theta)$, and degree of saturation (S) can be determined using the applicable equations. The method used for constructing the constitutive surfaces provided an opportunity to investigate the volume change behavior of unsaturated cracked soils in a simplified way. The constructed constitutive surfaces presented a general range of the unsaturated soil properties. These surfaces were principally modified versions of the currently available ones interposing the simulation of the soil as a dual porosity medium using a bimodal SWCC. The proposed curves can be easily adapted to practical problems. 


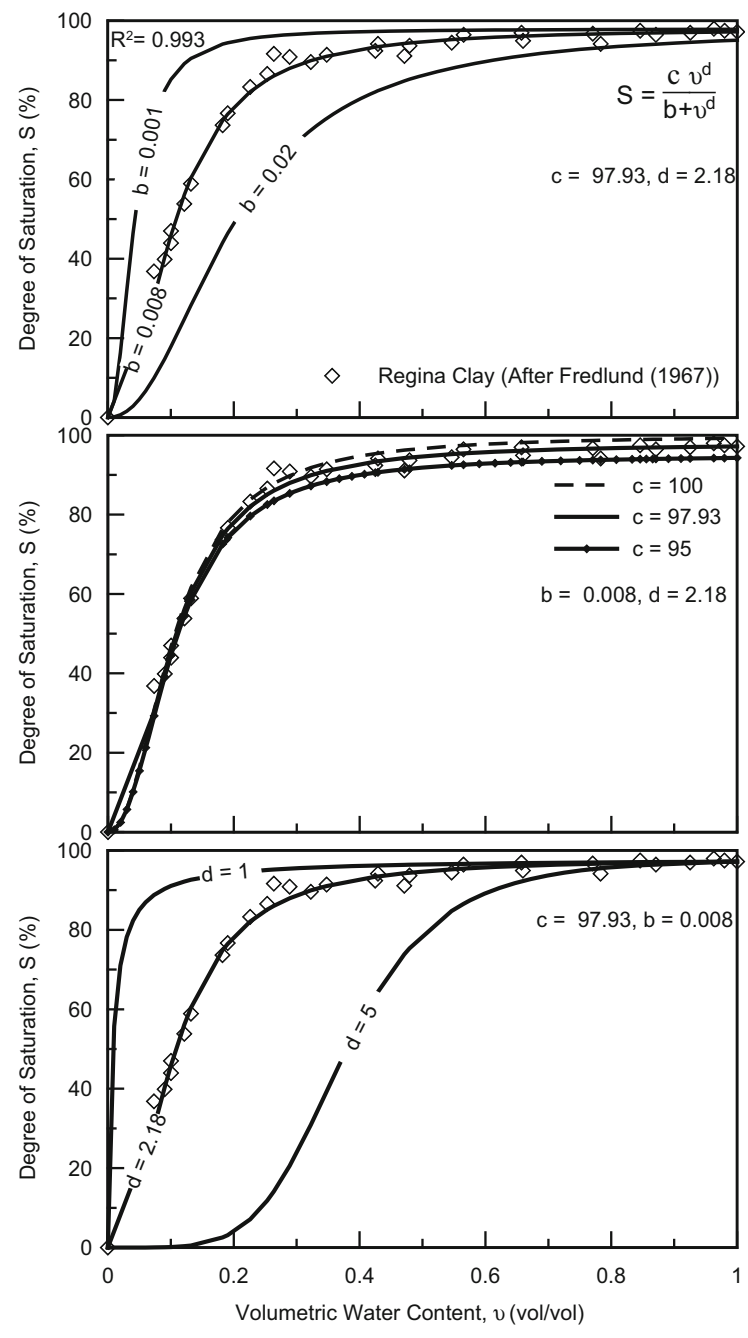

Fig. 16 Parametric analysis for the degree of saturation versus volumetric water content relationship

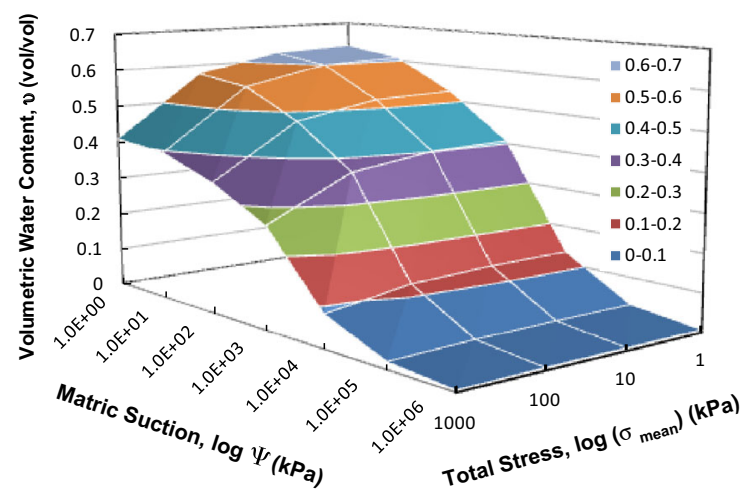

Fig. 17 Volumetric water content constitutive surfaces

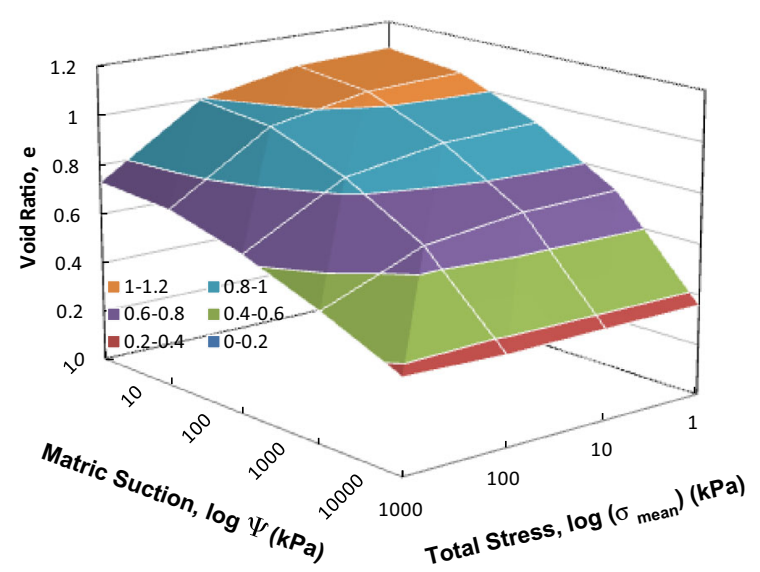

Fig. 18 Void ratio constitutive surfaces

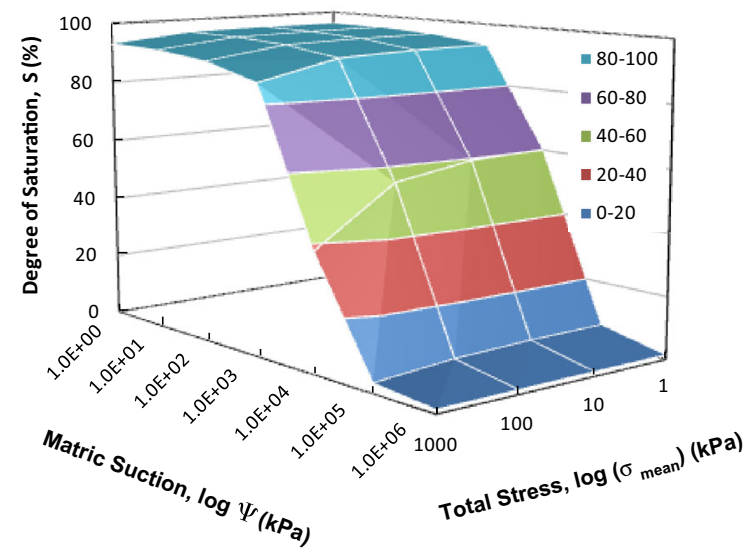

Fig. 19 Degree of saturation constitutive surfaces

\section{Water movement formulation}

The theory of modeling of in/exfiltration flux through soils was developed based on the law of conservation of mass. The hydraulic head gradient is defined as the driving force for water to flow through the soil structure from points of high total head to points of low total head. Other driving forces include moisture content and matric suction gradients. However, these gradients do not fundamentally govern the water movement through the soil structure (Fredlund and Rahardjo 1993b). Casagrande (1937) presented the flow net technique for predicting seepage through earth assuming that water only flows below the ground water level. Finite element methods have alternated the flow net technique due to their powerful nature. 
Due to the complexity of modeling seepage in saturated/unsaturated soils, It is viable to employ general partial differential equation solvers (Nguyen 1999). The rate of water flow in soils can be identified by using a generalization of Darcy's Law (Bear 1972) where the total head gradient and the hydraulic conductivity varies with matric suction. The generalized 2D form of Darcy's law can be expressed as presented in Eq. 11.

$\left[\begin{array}{l}q_{x} \\ q_{y}\end{array}\right]=-\left[\begin{array}{ll}K_{x x} & 0 \\ 0 & K_{y y}\end{array}\right]\left[\begin{array}{l}\frac{\partial h}{\partial x} \\ \frac{\partial h}{\partial y}\end{array}\right]$

where, $q_{x}$ and $q_{y}$ are liquid pore-water flow rates in the $\mathrm{x}$-, and $\mathrm{y}$-directions across a unit area of the soil due to the hydraulic head gradients $\left(\mathrm{m}^{3} / \mathrm{m}^{2} \mathrm{~s}\right), K_{x x}$, and $K_{y y}$ are hydraulic conductivity $(\mathrm{m} / \mathrm{s})$ in the $\mathrm{x}$-, and $\mathrm{y}$-directions, and $\mathrm{h}$ is the total hydraulic head (m).

Above the ground water table, the pressure heads are negative, and the hydraulic head can be determined indirectly through the field measurement of the suction head or negative pore-water pressure. Darcy's law can then be applied to the flow of water through unsaturated soils with the consideration of the change in the hydraulic conductivity (Richards 1931). There are different versions of Richards' equation for the determination of moisture movement through saturatedunsaturated soils. All these versions were mainly based on calculating water continuity in terms of matric suction. Equation 12 presents the two-dimensional partial differential form of Richards' equation.

$\frac{\partial}{\partial x}\left(k_{x} \frac{\partial h}{\partial x}\right)+\frac{\partial}{\partial y}\left(k_{y} \frac{\partial h}{\partial y}\right)=\frac{\partial \theta}{\partial t}$

where, $\mathrm{h}$ is the total head $(\mathrm{m}), \mathrm{k}_{\mathrm{x}}$ is the hydraulic conductivity $(\mathrm{m} / \mathrm{s})$ in the $\mathrm{x}$-direction, $\mathrm{k}_{\mathrm{y}}$ is the hydraulic conductivity $(\mathrm{m} / \mathrm{s})$ in the $y$-direction, and $\theta$ is the volumetric water content (VWC) (vol/vol).

Fredlund and Rahardjo (1993b) presented a general partial differential equation based on Richards' equation for the transient moisture flow through saturated/ un saturated soils as illustrated in Eq. 13.

$\frac{\partial}{\partial x}\left(k_{x} \frac{\partial h}{\partial x}\right)+\frac{\partial}{\partial y}\left(k_{y} \frac{\partial h}{\partial y}\right)=\gamma_{w} m_{2}^{w} \frac{\partial h}{\partial t}$

where, $\mathrm{h}$ is the total head $(\mathrm{m}), m_{2}^{w}$ is the slope of the soil-water characteristic curve (SWCC), and $\gamma_{w}$ is the unit weight of water $\left(\mathrm{kN} / \mathrm{m}^{3}\right)$.

\section{Parametric study}

\subsection{General description}

A parametric study was completed to characterize the effect of the change in unsaturated soil properties on the water seepage analysis for a soil column. The numerical model validated the reliability of the mathematical framework and quantified the effects of different boundary conditions. The modeling of soil moisture variation was based on the governing partial differential equations of seepage through saturatedunsaturated soils as discussed in the previous sections. The finite element modeling was implemented using the commercial finite element program FlexPDE (PDESolutionsInc. 2014). The FlexPDE's model script was written based on the developed mathematical framework and, then, the operations were performed by the program to transform the description form of the partial differential equations to a finite element model, run the analysis, and produce graphical output of the results. The mesh generating system associated with FlexPDE automatically created a finite element mesh fitting the problem domain. The primary advantage of using FlexPDE modeling software was that there was no uncertainty concerning the equations being solved compared with fixed-application programs.

\subsection{Methodology}

The soil column consisted of a highly plastic clay (Regina clay) over a clay till. The width and height of the column were 3 and $16 \mathrm{~m}$, respectively. The finite element mesh for the problem was generated by FlexPDE as presented in Fig. 20. Cell sizes were typically controlled by the spacing between explicit points in the domain boundary. The developed initial mesh consisted of triangular finite elements with an average size of $0.4 \mathrm{~m}$ over the arbitrary two-dimensional problem domain. Cell density in the initial mesh was managed by the mesh spacing and density parameters entered in the program. These parameters defined the maximum cell dimension and the minimum number of cells per unit distance.

A consistency check was then applied to the integrals of the partial differential equation over the mesh cells. The relative uncertainty of the solution was estimated and compared with the defined 


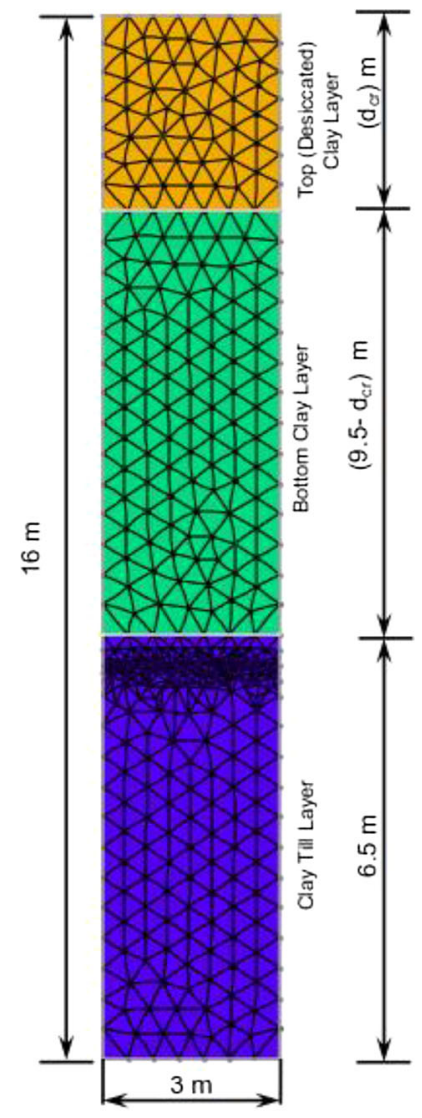

Fig. 20 Soil column configuration for the parametric study

accuracy tolerance of $0.01 \%$. When any mesh cell exceeded the tolerance, the cell was then refined, and the solution was re-computed until a defined error tolerance of $0.01 \%$ was achieved for every cell of the mesh. The seepage analysis was performed using the following boundary conditions:

- At the top of the column, a net flux was applied on the soil column. The magnitude of the applied flux was assumed to be $0.75,1$, and $2 \mathrm{~mm} /$ day;

- At bottom of the column, the net flux equaled zero;

- The sides of the column had no applied flow boundary condition;

- The highly plastic clay layer was divided into two layers, the upper layer extended to a depth of $\left(\mathrm{d}_{\mathrm{cr}}\right)$ representing the desiccated clay layer, and the bottom clay layer extended to a depth of $9.5 \mathrm{~m}$; and

- The initial VWC was assumed to be $0.3,0.36,0.25$ for the top clay, bottom clay, and clay till layers, respectively. The corresponding initial soil suction values were then determined to be 2800,1600 , and $1400 \mathrm{kPa}$, respectively.

The seepage modeling results were obtained in terms of soil parameters such as VWC and soil suction. The variation in these parameters as functions of both depth and time were obtained for the following depths below the ground surface, $1.5 \mathrm{~m}$ (within the top desiccated clay layer), $6.25 \mathrm{~m}$ (within the bottom clay layer), and $10 \mathrm{~m}$ (i.e., near the top of the clay till layer).

\subsection{Results and discussion}

A series of analyses using both unimodal and bimodal SWCCs were conducted under a net surface flux of $1 \mathrm{~mm} /$ day and a hydraulic conductivity factor of 1 as shown in Figs. 21 and 22. The pattern for the change in VWC was different, and roughly followed the shape of the utilized SWCC characteristics. It is clear that the use of bimodal SWCC resulted in a rapid reaction for the change in soil moisture conditions to the applied net flux in comparison with the unimodal SWCC. The top clay layer approached a full saturation condition in about five times the time required for the bimodal SWCC model.

The results suggest that the shape and characteristic of the SWCC have an influence on the outcome of the seepage analysis and, therefore, the SWCC should be formulated precisely to reflect the field conditions. Cracked soils were found to exhibit bimodal behavior because of the pore space distribution discrepancy in the soil matrix structure that is typically created by the cracks. The bimodal SWCC function resulted in allowing greater infiltration and was considerably different from the unimodal one. Therefore, it is clear that the use bimodal SWCC provided a more practical method for the simulation of the soil-water interaction for highly plastic clays.

At a depth of $1.5 \mathrm{~m}$ and under a net surface flux of $1 \mathrm{~mm} /$ day and maximum cracking factor $\left(f_{\max }\right)$ values of 1,50 , and 200, the variation in the resulting hydraulic conductivity factor and the hydraulic conductivity of the top clay were plotted with time as shown in Figs. 23 and 24. The initial hydraulic conductivity of the clay was in the order of $10^{-12} \mathrm{~m} / \mathrm{s}$. The resulting initial hydraulic conductivity of the clay was in the order of 


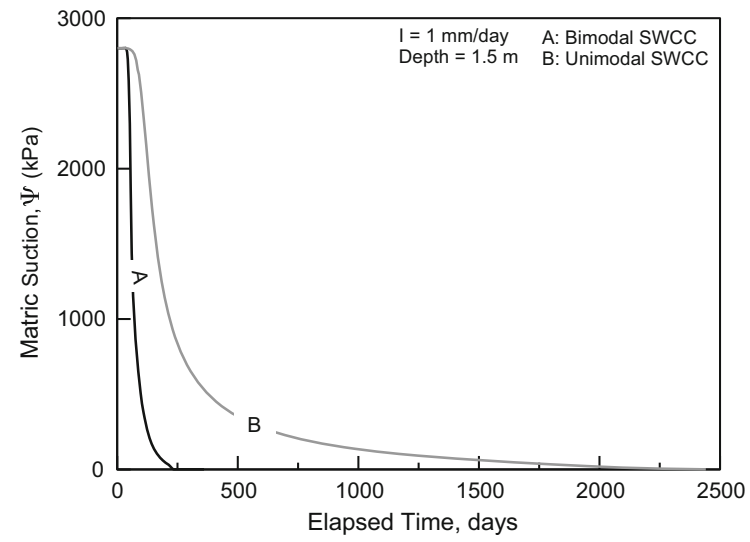

Fig. 21 Predicted suction profiles for Bimodal SWCC versus Unimodal SWCC

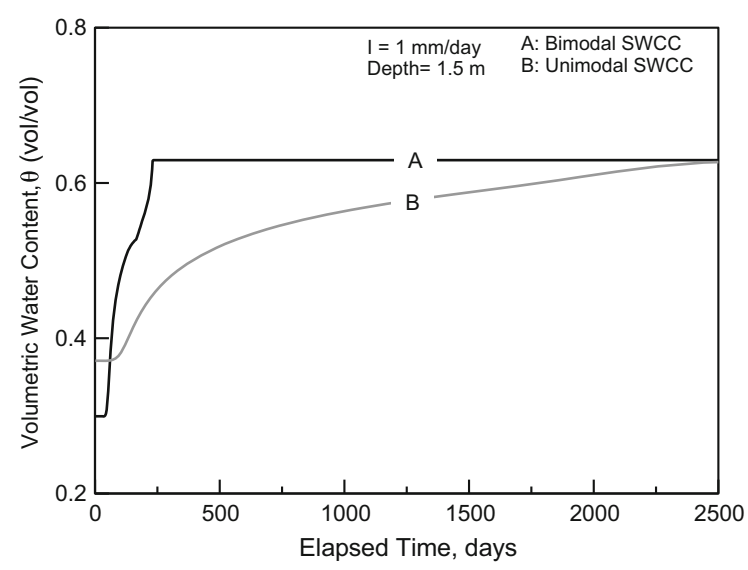

Fig. 22 Predicted volumetric water content profiles for bimodal SWCC versus unimodal SWCC

$10^{-10} \mathrm{~m} / \mathrm{sec}$ (i.e., an increase of two orders of magnitude), and $10^{-11} \mathrm{~m} / \mathrm{s}$ (i.e., an increase of one order of magnitude) corresponding to $\mathrm{f}_{\max }$ of 200 and 50 , respectively. The hydraulic conductivity was almost the same after approximately 235 days when the soil approached near saturation condition. Figure 25 shows the variation in soil suction with the change in the hydraulic conductivity of the clay. When $\mathrm{f}_{\max }$ increased from 50 to 200 , the change in soil suction was not as noticeable as when increasing from 1 to 50. In addition, as the hydraulic conductivity increased, the change in the VWC took place in less time. This overall behavior was reasonably able to model the dynamicity of the change in soil hydraulic characteristics with the formation/discontinuation of soil cracks.

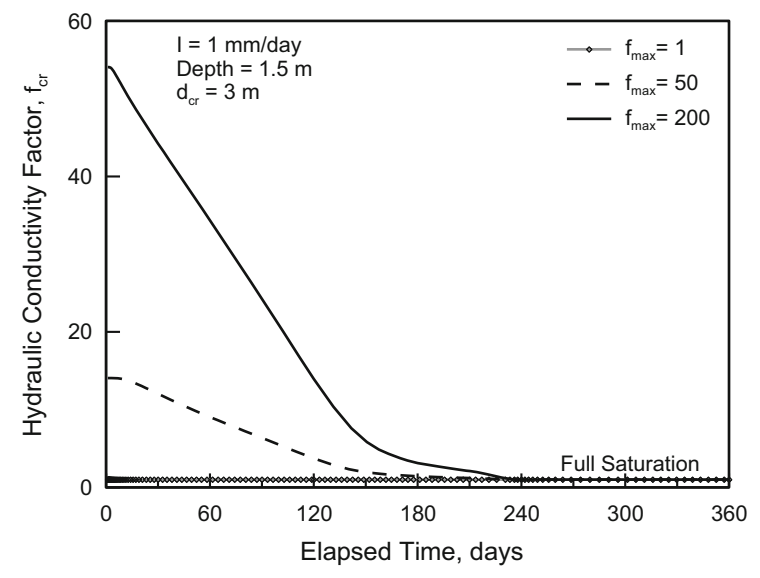

Fig. 23 Hydraulic conductivity factor versus elapsed time

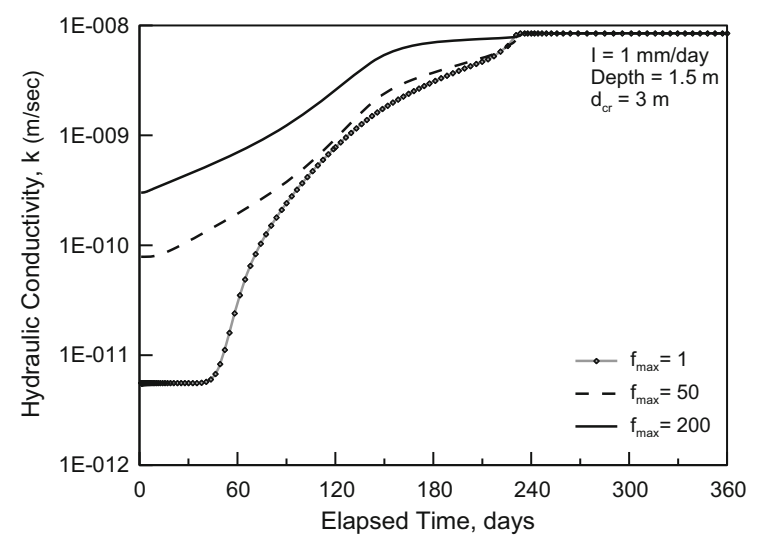

Fig. 24 Hydraulic conductivity versus elapsed time

The change in soil moisture was studied for different cases where the hydraulic cracking factor was applied to different soil depths representing the increase in the depth of the top desiccated clay layer. Using a maximum cracking factor $\left(f_{\max }\right)$ of 50 , the change in soil moisture characteristics were predicted for different cracking depths of 1,2, and $3 \mathrm{~m}$ as shown in Fig. 26. There were noticeable differences in the VWC profiles with the increase in the cracking depth. Due to the increase in the hydraulic conductivity, the change in VWC started earlier and resulted in higher VWC magnitudes. However, after a certain time period (approximately 50 days), increasing the cracking depth resulted in lower VWC magnitudes. This behavior reflected the effect of the change in the seepage process of a cracked soil structure versus an 


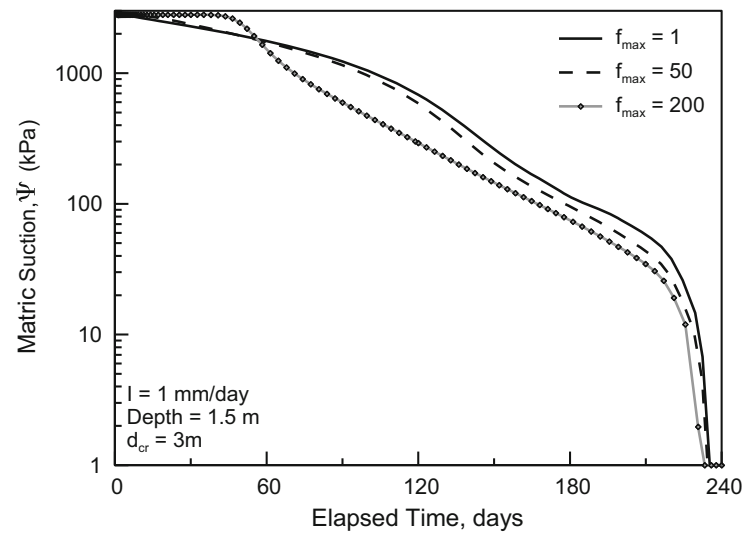

Fig. 25 Predicted suction versus elapsed time at different cracking factor magnitudes

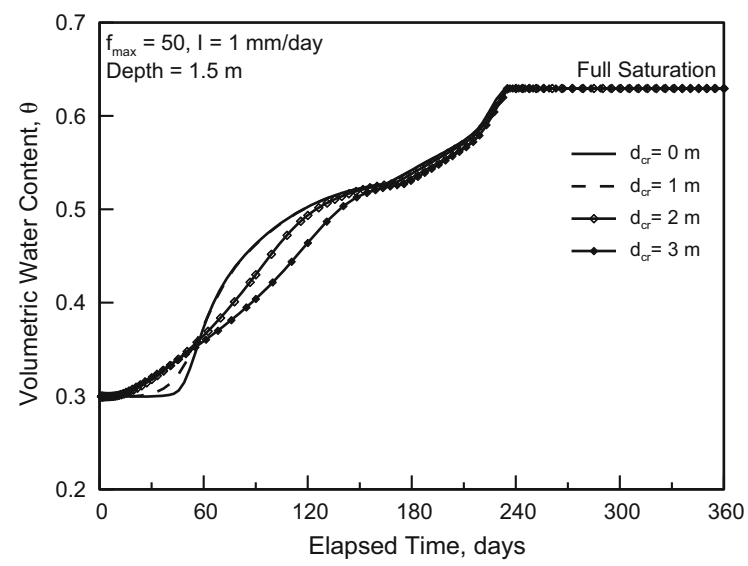

Fig. 26 Predicted volumetric water content versus elapsed time at different cracking depths

un-cracked soil. When the soil is cracked to a certain depth, the water seepage is expected to be more rapid, and water reaches greater depth.

After approximately 140 days, the resulting VWC profile was almost the same with the increase in the cracking depth reflecting the small effect of soil cracking when the soil reached near saturation condition. This behavior corresponded to the change in hydraulic conductivity factor with time as defined earlier in Eq. 10. These results demonstrate the significance of properly defining the depth of cracking in soil-water interaction analysis.

Figures 27 and 28 show the variation in VWC and soil suction with time at three different depth of 1.5 , 6.26 , and $10 \mathrm{~m}$ below the surface. In general, there

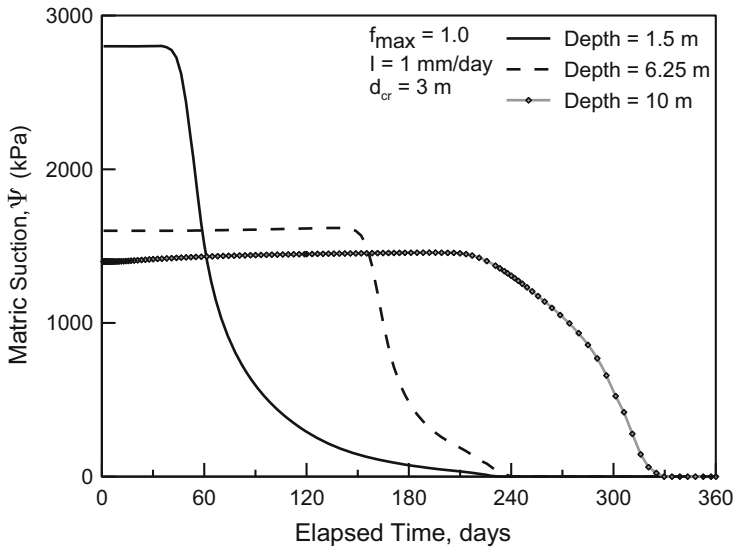

Fig. 27 Predicted suction versus elapsed time at different soil depths

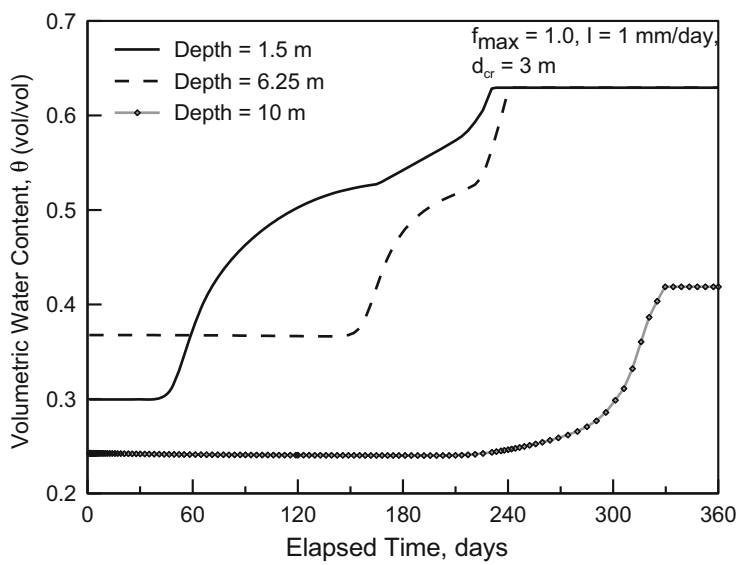

Fig. 28 Predicted volumetric water content versus elapsed time at different soil depths

was an increase in VWC with time as a result of the water seepage process. The VWC gradually increased until it reached constant values corresponding to full saturation. The change in VWC followed a bimodal pattern. A time delay for the start of the change in VWC occurred and increased with the increase in depth reflecting the time at which the soil-water interaction started. Likewise, the time required to reach saturation was different at each level.

Finally, the effect of the change in the applied surface flux was also investigated as shown in Figs. 29 and 30. Both VWC and soil suction gradually changed with time and finally reached constant values corresponding to those values at full saturation. There were differences in time at which the soil became saturated 


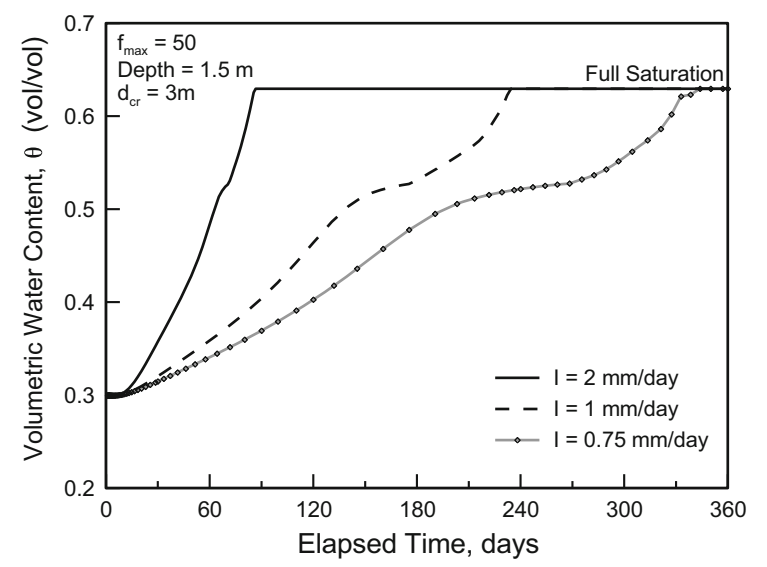

Fig. 29 Predicted volumetric water content versus elapsed time at different net surface flux magnitudes

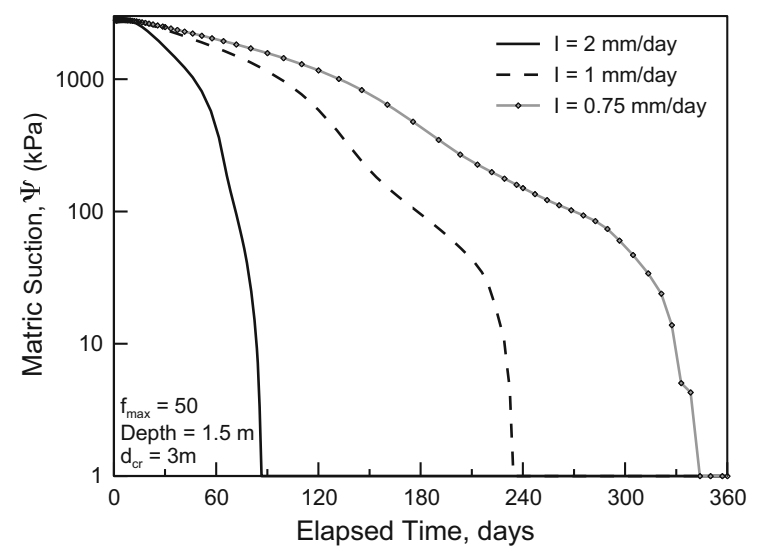

Fig. 30 Predicted suction versus elapsed time at different net surface flux magnitudes

for the different applied net fluxes. Increasing the magnitude of the applied flux resulted in a rapid soil saturation progression. However, the variation in VWC and soil suction followed almost the same pattern.

\section{Conclusions}

This technical paper provided a comprehensive theoretical framework for the mathematical formulation of unsaturated soil properties. The soil-water characteristic curve (SWCC) and hydraulic conductivity function were formulated for a highly plastic clay to reflect the field conditions. The volume-mass constitutive relationships were also established to provide a clear understanding of the saturated-unsaturated soil behavior under changes in net normal stress and soil suction. In addition, the sensitivity of transient seepage modeling to changes in the characteristics of the SWCC and hydraulic conductivity were intensively investigated.

The main conclusions of the study can be summarized as follows:

- The soil moisture content test results demonstrated that the upper 2-3 $\mathrm{m}$ of the clay in the study area had a moisture content that was less than the plastic limit. Surficial cracks were also observed within this layer in the field. In addition, based on the performed theoretical analysis, a cracking depth of up to $3 \mathrm{~m}$ would be highly expected.

- Using the bimodal SWCC, the soil behavior can be modeled as a dual-porosity medium. The developed bimodal SWCC consisted of two SWCC functions along with their distinct parameters representing the intact part of the soil and the cracked fraction.

- Volume-mass constitutive relationships were established based on the bimodal SWCC and representative consolidation results. These relationships were used to predict the saturatedunsaturated soil properties under changes in soil suction and net normal stress. The volume-mass constitutive relationships led to improved predictions of the soil-water interaction.

- A seepage model was effectively established to simulate the development of soil cracks as a dynamic process and as a function of the soilwater interaction process. The seepage modeling study demonstrated that:

- The SWCC is a critical property affecting the modeling of the soil-water interaction and has a significant influence on the seepage modeling results. The bimodal SWCC provided a practical technique for the simulation of the soilwater interaction for cracked soils. The use of bimodal SWCC reflected the increase in water infiltration because of the pore space distribution discrepancy in the soil matrix structure that is created by the cracks. In addition, the bimodal SWCC resulted in a rapid change in the volumetric water content (VWC) with time compared with the unimodal one.

- The hydraulic conductivity factor defined as a function of the soil suction provided a 
reasonable demonstration of the increase in the hydraulic conductivity of the desiccated clay layer. The increase in soil depth within which the hydraulic conductivity factor was applied, representing the increase in the vertical extent of soil cracks, caused the change in soil moisture to reach a greater depth.

- Both VWC and soil suction gradually changed with time, and finally achieved a constant value of the full saturation condition. The variations in VWC and soil suction followed the same pattern with the increase in the applied net flux.

Acknowledgments The authors would like to acknowledge the contribution of the National Research Council Centre for Sustainable Infrastructure Research for allowing access to their research facilities. We would like to thank Dr. Yafei Hu for his overall guidance in the research program. The first author also would like to thank the Faculty of Graduate Studies and Research (FGSR) at the University of Regina, and the City of Regina (Henry Baker Scholarship Program) for providing additional financial support.

\section{References}

Albrecht BA, Benson CH (2001) Effect of desiccation on compacted natural clays. J Geotech Geoenviron Eng 127:67-75

Anderson T (2005) Fracture mechanics: fundamentals and applications. CRC press, Florida, p 610

Anderson D (2010) Vertisolic soils of the Prairie Region. Prairie Soils Crops 3:29-36

Bear J (1972) Dynamics of fluids in porous media. Dover Science, New York

Bishop AW, Blight G (1963) Some aspects of effective stress in saturated and partly saturated soils. Geotechnique 13:177-197

Blight G, Williams A (1971) Cracks and fissures by shrinkage and swelling. Paper presented at the Proceedings of the 5th Reg. Conference for Africa on Soil Mech. Found. Eng. (Angola)

Briones A, Uehara G (1977) Soil elastic constants: II. Application to analysis of soil cracking. Soil Sci Soc Am J 41:26-29

Casagrande A (1937) Seepage through dams. N Engl Water Works 51:295-336

Childs EC, Collis-George N (1950) The permeability of porous materials. In: Proceedings of the royal society of London A: mathematical, physical and engineering sciences series A, pp 392-405

Christiansen EA (1979) The Wisconsinan deglaciation, of southern Saskatchewan and adjacent areas. Can J Earth Sci 16:913-938
Christiansen E, Sauer EK (2002) Stratigraphy and structure of Pleistocene collapse in the Regina Low, Saskatchewan, Canada. Can J Earth Sci 39:1411-1423

Corte A, Higashi A (1964) Experimental research on desiccation cracks in soil. Wilmette, Illinois

de FN Gitirana G Jr, Fredlund DG (2004) Soil-water characteristic curve equation with independent properties. J Geotech Geoenviron Eng 130:209-212

Durner W (1994) Hydraulic conductivity estimation for soils with heterogeneous pore structure. Water Resour Res 30:211-223

Elkady TY (2014) Unsaturated characteristics of undisturbed expansive shale from Saudi Arabia. Arab J Geosci 7:2031-2040

Fredlund DG (1967) Comparison of soil suction and one-dimensional consolidation characteristics of a highly plastic clay. Canada

Fredlund DG, Rahardjo H (1993a) An overview of unsaturated soil behaviour. Geotechnical Special Publication, American Society of Civil Engineers (ASCE), pp 1-31

Fredlund DG, Rahardjo H (1993b) Soil mechanics for unsaturated soils. Wiley, New York

Fredlund DG, Xing A (1994) Equations for the soil-water characteristic curve. Can Geotech J 31:521-532

Fredlund DG, Houston SL, Nguyen Q, Fredlund MD (2010) Moisture movement through cracked clay soil profiles. Geotech Geol Eng 28:865-888

Fredlund MD, Wilson GW, Fredlund DG (2002) Use of the grain-size distribution for estimation of the soil-water characteristic curve. Can Geotech J 39(5):1103-1117

Gallage C, Kodikara J, Uchimura T (2013) Laboratory measurement of hydraulic conductivity functions of two unsaturated sandy soils during drying and wetting processes. Soils Found 53:417-430

Gardner W (1958) Some steady-state solutions of the unsaturated moisture flow equation with application to evaporation from a water table. Soil Sci 85:228-232

Griffith AA (1921) The phenomena of rupture and flow in solids. Philosophical transactions of the royal society of London Series A, containing papers of a mathematical or physical character, pp 163-198

Hanson JA, Hardin BO, Mahboub K (1994) Fracture toughness of compacted cohesive soils using ring test. J Geotech Eng 120:872-891

Hazen A (1892) Some physical properties of sands and gravels: with special reference to their use in filtration. Massachusetts State Board of Health, Boston, Mass., USA

$\mathrm{Hu} \mathrm{Y}, \mathrm{Vu}$ HQ (2011) Analysis of soil conditions and pipe behaviour at a field site. Can Geotech J 48:847-866

Johnston K, Haug M (1992) Impact of wet-dry freeze-thaw cycles on the hydraulic conductivity of glacial till. Paper presented at the Proceedings of the 45th Canadian Geotechnical Conference, Toronto, Canada

Kodikara J, Barbour S, Fredlund DG (2002) Structure development in surficial heavy clay soils: a synthesis of mechanisms. Aust Geomech 23:25-40

Köhne JM, Köhne S, Gerke H (2002) Estimating the hydraulic functions of dual-permeability models from bulk soil data. Water Resourc Res 38:26-21-26-11 
Lau J (1987) Desiccation cracking of clay soils. M. Sc. thesis, Department of Civil Engineering, University of Saskatchewan, Saskatoon, Canada

Leong EC, Rahardjo H (1997) Permeability functions for unsaturated soils. J Geotech Geoenviron Eng 123:1118-1126

Matyas EL, Radhakrishna H (1968) Volume change characteristics of partially saturated soils. Géotechnique 18:432-448

Miller CJ, Mi H, Yesiller N (1998) Experimental analysis of desiccation crack propagation in clay liners. J Am Water Resour Assoc 34:677-686

Mitchell J (1993) Fundamentals of soil behavior. Wiley, New York

Mollard J, Kozicki P, Adelman T (1998) Some geological, groundwater, geotechnical and geoenvironmental characteristics of the Regina area, Saskatchewan, Canada. Urban geology of Canadian cities

Morris PH, Graham J, Williams DJ (1992) Cracking in drying soils. Can Geotech J 29:263-277

Nahlawi H, Kodikara J (2006) Laboratory experiments on desiccation cracking of thin soil layers. Geotech Geol Eng 24:1641-1664

$\mathrm{Ng} \mathrm{CW}$, Menzies B (2007) Advanced unsaturated soil mechanics and engineering. CRC Press, Boca Raton

Nguyen T (1999) Solution of saturated/unsaturated seepage problems using a general partial differential equation solver. M. Sc. thesis, University of Saskatchewan, Saskatoon, Sask

Novak V, Šimåunek J, Genuchten MTV (2000) Infiltration of water into soil with cracks. J Irrig Drain Eng 126:41-47

PDESolutionsInc. (2014) FlexPDE user guide http://www. pdesolutions.com. Accessed June 2013

Pham HQ (2005) A volume-mass constitutive model for unsaturated soils. Ph.D. Dissertation, University of Saskatchewan
Raats P (1984) Mechanics of cracking soils. In: Proceedings ISSS symposium on water and solute movement in heavy clays soils, The Netherlands, pp 23-38

Reynolds W (1993) Unsaturated hydraulic conductivity, field measurement. In: Soil sampling and methods of analysis, Lewis Publishers, USA, pp 633-644

Richards LA (1931) Capillary conduction of liquids through porous mediums. J Appl Phys 1:318-333

Satyanaga A, Rahardjo H, Leong E-C, Wang J-Y (2013) Water characteristic curve of soil with bimodal grain-size distribution. Comput Geotech 48:51-61

Vanapalli S, Pufahl D, Fredlund D (1998) The effect of stress state on the soil-water characteristic behavior of a compacted sandy-clay till. Paper presented at the Proceedings of the 51st Canadian Geotechnical Conference, Edmonton, Canada

Wang J-J, Zhu J-G, Chiu C, Zhang H (2007) Experimental study on fracture toughness and tensile strength of a clay. Eng Geol 94:65-75

White WA (1949) Atterberg plastic limits of clay minerals. Report of investigations no 144

Wilson G, Fredlund M (2000) The application of knowledgebased surface flux boundary modeling. Paper presented at the conference on unsaturated soils for Asia, Rahardjo, Toll\&Leong (Eds)

Yesiller N, Miller C, Inci G, Yaldo K (2000) Desiccation and cracking behavior of three compacted landfill liner soils. Eng Geol 57:105-121

Zhang X (2004) Consolidation theories for saturated-unsaturated soils and numerical simulations of residential buildings on shrink-swell soils. Ph.D. Dissertation, Department of Civil Engineering, Texas A\&M University, College Station, TX

Zhang L, Chen Q (2005) Predicting bimodal soil-water characteristic curves. J Geotech Geoenviron Eng 131:666-670 